\title{
The $\mathrm{BH} 3$ domain is required for caspase-independent cell death induced by Bax and oligomycin
}

\author{
ME Fitch ${ }^{1}$, C-M Chang ${ }^{1}$ and TG Parslow ${ }^{\star, 1,2}$ \\ 1 Department of Pathology and Biomedical Sciences Program, University of \\ California, San Francisco, California, CA 94143-0506 USA; \\ 2 Department of Microbiology and Immunology, University of California, San \\ Francisco, California, CA 941430-506 USA \\ * Corresponding author: TG Parslow, Department of Pathology, Box 0506, \\ University of California, San Francisco CA 94143 USA. \\ Tel: (415) 476-1015; Fax: (415) 476-9672; E-mail: parslow@cgl.ucsf.edu
}

Received 6.8.99; revised: 24.11.99; accepted: 20.12 .99

Edited by $D$ Green

\begin{abstract}
Bax causes apoptosis by associating with mitochondria and triggering cytochrome $c$ release, which activates the caspase cascade. Bax can also kill some cells independently of caspases, but the requirements for such killing are poorly understood. Here we describe an inducible fibroblast line that expresses Bax when tetracycline is withdrawn; the resulting apoptosis can be blocked by the caspase inhibitor ZVAD-fmk. Even when caspases are inhibited, however, treating the Baxexpressing cells with the mitochondrial toxin oligomycin efficiently triggers death with features resembling apoptosis. Bax mutants lacking the $\mathrm{BH} 3$ domain remain able to cause cytochrome $c$ release and caspase-mediated death, but cannot support this caspase-independent killing. Mutating specific BH3 residues needed for binding Bcl2 does not prevent synergy with oligomycin, implying that no such binding is required. These findings illuminate a caspaseindependent pathway of death that depends on the Bax BH3 domain and on effectors emanating from mitochondria. Cell Death and Differentiation (2000) 7, 338-349.
\end{abstract}

Keywords: apoptosis; Bax; caspase; cytochrome c; mitochondria

\begin{abstract}
Abbreviations: ATPase, adenosine triphosphatase; $\beta$-gal, $\beta$ galactosidase; cyto $\mathrm{c}$, cytochrome $\mathrm{c} ; \Delta \Psi_{\mathrm{m}}$, mitochondrial transmembrane potential; DAPI, 4',6-diamidino-2-phenylindole; FACS, fluorescence activated cell sorting; FITC, fluorescein isothiocyanate; GAPDH, glyceraldehyde 6-phosphate dehydrogenase; HA, influenza hemagglutinin; PAGE, polyacrylamide gel electrophoresis; PARP, poly(ADP ribosyl) polymerase; Tet, tetracycline; zVAD-fmk, benzyloxycarbonyl-Val-Ala-Asp-fluoromethyl ketone
\end{abstract}

\section{Introduction}

Mitochondria have been implicated as key components of the apoptotic machinery (reviewed $\mathrm{in}^{1}$ ). Early evidence of their involvement came from the finding that cytochrome $\mathrm{c}$ (cyto c), a soluble protein that normally resides between the inner and outer mitochondrial membranes, is released into the cytoplasm in response to many apoptotic stimuli; cyto c release, in turn, leads to activation of caspase-9, which activates the downstream caspase cascade. ${ }^{2,3}$ Subsequent studies indicate that mitochondria can store and release other apoptogenic factors as well, including certain pro-caspases. ${ }^{4-6}$ A variety of apoptotic signals act through mitochondria: caspase activation itself can trigger cyto $c$ release from these organelles to amplify an ongoing response, but other death signals, including ultraviolet radiation and staurosporine, mobilize cyto $c$ independently of caspases. ${ }^{7}$ Mitochondria also appear to be the primary locus of action for the $\mathrm{Bcl} 2$ family of apoptotic regulatory proteins. ${ }^{8,9}$ For example, the anti-apoptotic activity of Bcl2 reflects in part its capacity to suppress cyto $c$ release from these organelles. ${ }^{10,11}$ By contrast, certain pro-apoptotic family members, such as Bax and tBID, are potent inducers of cyto $c$ release, and translocate rapidly from the cytoplasm onto mitochondria soon after apoptotic stimulation. $^{12-18}$

Mitochondria thus serve to integrate many different types of death signals and, by virtue of their ability to activate caspase-9, couple these signals to the caspase cascade. There is, however, some evidence that these organelles can access other active cell-death pathways that do not depend on caspase activation. In particular, two groups have reported that overexpressing Bax can induce rapid killing of lymphoid cells even when caspase activity is blocked. ${ }^{19,20}$ Bax also can kill yeast cells, which express no known caspases. ${ }^{21}$ In this report, we describe a fibroblast cell line that undergoes caspase-independent death with certain features of apoptosis when exposed to the combination of Bax and the mitochondrial toxin oligomycin. Our findings confirm the existence of a mitochondriallymediated death pathway that functions independently of caspase activation.

\section{Results}

\section{Inducible Bax expression in GM701 fibroblasts}

To study the mechanisms of Bax-induced death, we transfected the human GM701 fibroblast cell line with an HA-epitope-tagged mouse Bax cDNA under the control of a tetracycline-repressible promoter. A gene cassette conferring hygromycin resistance was introduced simultaneously, and stably transfected colonies selected first for growth in hygromycin and tetracycline (Tet) were then screened to identify those that died following Tet withdrawal. Our initial analysis utilized one stable clone (designated I-Bax) which demonstrated an especially marked death response when Tet was withdrawn; major findings were later confirmed using transiently transfected populations of the parental cells. As expected, withdrawing Tet from I-Bax cells caused increased 
expression of both the HA-tagged Bax protein and its mRNA within $24 \mathrm{~h}$, as judged from immunoblots (Figure 1A) and Northern blots (Figure 1B) that specifically detected products of the transgene. This induction was verified by HA-specific immunoprecipitation from biosynthetically radiolabelled cells, which revealed that synthesis of the tagged Bax protein increased markedly as early as $12 \mathrm{~h}$ after drug withdrawal (Figure 1C). Even before withdrawal, levels of the tagged protein and mRNA were higher in I-Bax than in GM701 cells that had been transfected with the hygromycin-resistance marker only (Hygro), implying that Tet repression of the Bax gene was incomplete. The I-Bax cells appeared unaffected by this low background expression of the transgene, as their basal rates of growth and their sensitivities to apoptotic stimuli such as staurosporine and ionizing radiation were comparable to those of Hygro or GM701 cells (data not shown). GM701 parental cells contain endogenous Bax (Figure 1D), which suggests that the additional basal expression from the epitope-tagged transgene can be tolerated through countervailing mechanisms that are already present in the cell.

Soon after Tet-withdrawal, the I-Bax cells began to exhibit changes typical of apoptosis. For example, the percentage of cells that bound annexin $\mathrm{V}$ (Figure 2A), showed a reduced mitochondrial transmembrane potential

$\mathbf{A}$

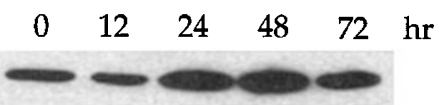

$+\mathrm{zVAD}$

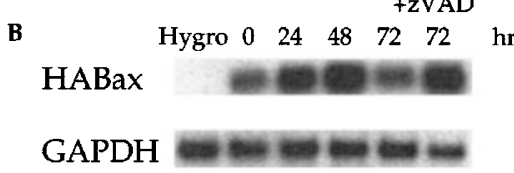

C
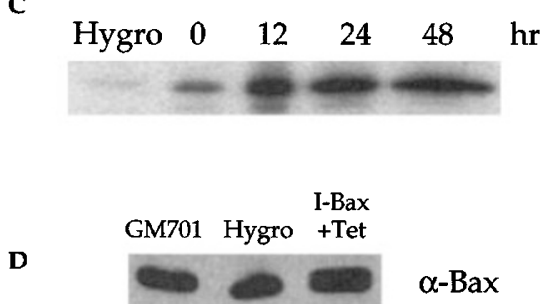

Figure 1 HA-Bax protein and mRNA levels in I-Bax cells rise following withdrawal of Tet. Extracts were prepared either from Hygro control cells (Hygro), or from I-Bax cells at the indicated times following Tet-withdrawal. (A) Induction of HABax protein. Whole-cell lysates prepared from Bax cells were fractionated by PAGE and immunoblotted using an HA-specific antibody. (B) Northern blot analysis of HABax mRNA induction. RNA harvested from cell lysates was probed for sequences at the unique $5^{\prime}$ end of the transgene (HABax) or for endogenous GAPDH sequences (GAPDH). For the ' $+\mathrm{ZVAD}$ 72 h' sample, zVAD-fmk was added to I-Bax cells at the time of Tet-withdrawal and then was replenished daily. (C) New synthesis of HABax protein. Hygro or I-Bax cells were incubated with ${ }^{35} \mathrm{~S}$-methionine for $6 \mathrm{~h}$ prior to harvest; cell lysates were then immunoprecipitated with HA-specific antibody, and the precipitates were fractionated by PAGE and analyzed by autoradiography. (D) Total Bax expression in cell lines. Whole-cell lysates were prepared from GM701, Hygro and I-Bax cells, fractionated by PAGE and immunoblotted using a Bax-specific antibody. The 'I-Bax+Tet' sample shows a doublet composed of the epitope-tagged (upper) and endogenous (lower) Bax proteins
$\left(\Delta \Psi_{\mathrm{m}}\right)$ as assayed using the lipophilic fluorescent dye $\mathrm{DiOC}_{6}$ (Figure 2B), or failed to exclude trypan blue (data not shown) increased significantly within $24 \mathrm{~h}$ after drug withdrawal. Caspase activation could be detected as early as $12 \mathrm{~h}$ post-withdrawal, as evidenced by cleavage of endogenous PARP protein (Figure 2C). Although the percentage of cells actively undergoing apoptosis as measured by these assays peaked at 20-25\% after $72 \mathrm{~h}$, the cumulative effect of the ongoing deaths was more apparent in the growth kinetics of the population, in that net proliferation of the cells was reduced by more than $70 \%$ after 3 days without Tet (Figure 2D). The rate of apoptosis was further augmented if the cells were passaged during this time, so that no viable cells remained after two passages without Tet over 5-6 days (data not shown).

\section{Caspases and Bax-induced apoptosis}

The apoptosis of Tet-deprived I-Bax cells was fully inhibitable by zVAD-fmk, a broad-spectrum caspase inhibitor. As illustrated in Figure $3 \mathrm{~A}$, we found that adding $40 \mu \mathrm{M}$ zVAD$\mathrm{fmk}$ to the culture medium at the time of Tet withdrawal completely suppressed the apoptotic response, as assayed in flow cytometric assays for surface annexin $\mathrm{V}$ binding, for $\Delta \Psi_{\mathrm{m}}$ using $\mathrm{DiOC}_{6}$, or for nuclear DNA content. In each of these assays, the percentage of apoptotic cells at $72 \mathrm{~h}$ postwithdrawal was reduced from $22-25 \%$ in the absence of zVAD-fmk to $3-6 \%$ in its presence (Figure $3 A$ ); the latter values are indistinguishable from background levels seen prior to Tet withdrawal or in parental GM701. Comparable inhibition could also be achieved by treating the cells with a combination of two different peptide inhibitors (at $40 \mu \mathrm{M}$ each) that together inhibit caspases 8 and 9 selectively. Using a more sensitive FACS assay based on the fluorescent dye JC1, we were able to detect a subtle effect of Bax on mitochondrial function which persisted despite caspase inhibition: $24 \mathrm{~h}$ of Tet withdrawal alone caused a significant loss of $\Delta \Psi_{\mathrm{m}}$ (reflected in a decrease in red emission from JC-1 dimers), which was essentially unaffected by zVAD-fmk (Figure 3B).

\section{Bax effects on the mitochondria}

To verify the interaction of Bax with mitochondria in the presence of caspase inhibitors, we utilized indirect immunofluorescence with a primary antiserum directed specifically against the HA-epitope tag on the transgenic Bax. All cells were additionally stained with a second primary antiserum that recognized cyto $\mathrm{c}$. In I-Bax cells growing in Tet, cyto $\mathrm{c}$ was present within mitochondria, and no HA-tagged Bax was detectable, presumably because it was scarce and dispersed throughout the cytosol (data not shown). After $24 \mathrm{~h}$ of Tet withdrawal in the presence of zVAD-fmk (Figure 4), HABax immunoreactivity (red) was detected in two distinct patterns. In certain cells, HABax colocalized with intramitochondrial cyto $c$ (green) in a dispersed punctate pattern (Figure 4, upper panels); in the majority of cells, HABax-positive mitochondria were found aggregated in a dense perinuclear cluster, but failed to stain for cyto $c$, which had presumably been 
A

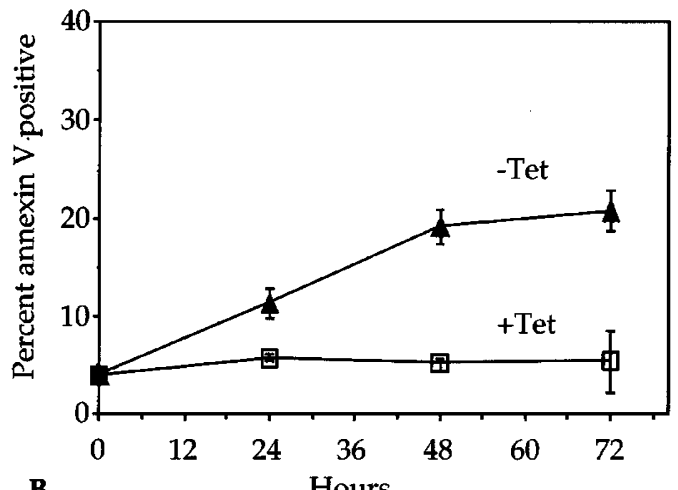

B

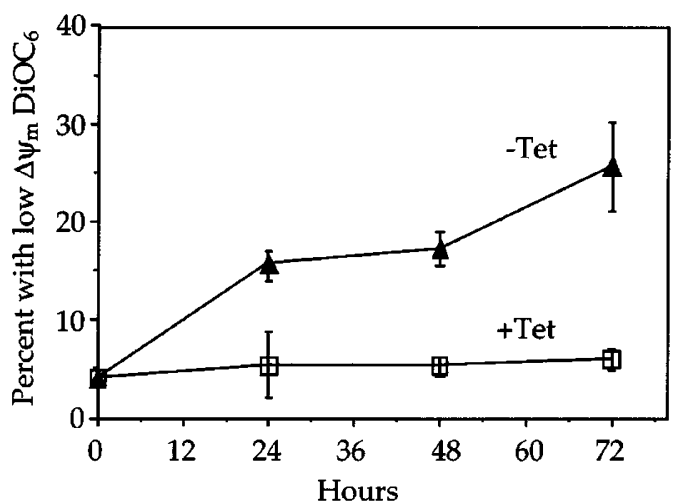

C

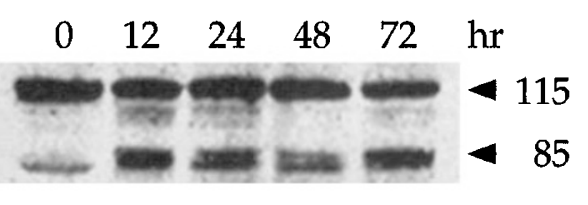

D

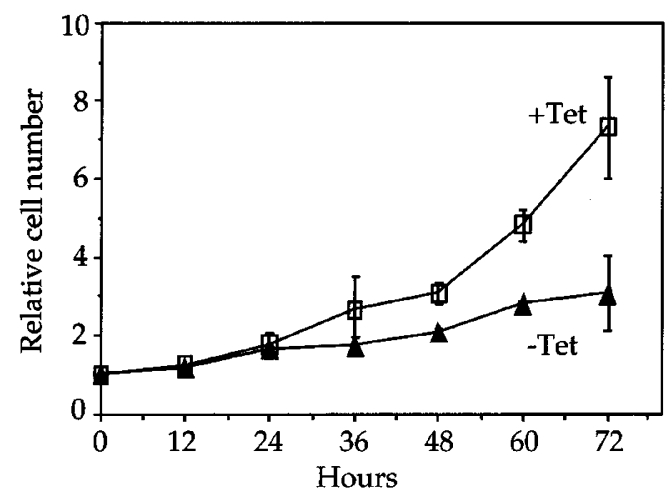

Figure 2 Withdrawal of Tet induces apoptosis in I-Bax cells. I-Bax cells were analyzed after growth for indicated times with or without Tet. (A) Percentage of cells with exposed surface phosphatidylserine was quantified by FACS using annexin V-FITC. (B) Percentage of cells exhibiting a reduced $\triangle \Psi_{m}$ was assayed by FACS using the dye $\mathrm{DiOC}_{6}$. (C) Cleavage of endogenous PARP protein, a caspase substrate. Cell lysates were prepared at the indicated times after Tet-withdrawal, fractionated by PAGE, and immunoblotted using mouse anti-PARP antibody. Arrows denote the 115-kD full-length PARP (upper) and 85-kD cleavage product (lower). (D) Growth kinetics were assayed by visually counting viable (trypan blue-negative) cell density in duplicate experiments, expressed as a multiple of the initial plating density

discharged into the cytosol (Figure 4, lower panels). The identity of the clustered organelles was confirmed by staining with MitoTracker green, a mitochondrion-specific dye (data not shown). The latter staining pattern was seen in $64 \%$ of the HA positive cells at $24 \mathrm{~h}$, and $79 \%$ of the positive cells at $72 \mathrm{~h}$ after-Tet withdrawal. This temporal progression suggests that the newly-synthesized HABax protein rapidly associates with mitochondria, which subsequently release cyto $c$ and cluster near the nucleus without the requirement of caspase activation. This confirms earlier reports ${ }^{15,22}$ which also found that blocking caspase activation using zVAD-fmk did not prevent Bax- or Bid-induced release of cyto $\mathrm{C}$. Thus, when caspases are inhibited, Bax can cause some perturbations of mitochondrial function in these cells, but fails to induce apoptosis.

\section{Caspase-independent death induced by oligomycin together with Bax}

We then asked whether other substances that targeted the mitochondria could function synergistically with Bax. In particular, we tested the effects of two potent mitochondrial toxins-oligomycin and antimycin-which inhibit the $F_{1} F_{0^{-}}$ adenosine triphosphatase (-ATPase) and complex III of the electron transport chain, respectively. Typical results are shown in Figure 5. At the concentrations tested, each agent by itself produced little or no increase in death of I-Bax cells growing in Tet, or of Hygro cells, as measured by surface annexin $\mathrm{V}$ binding and by staining with propidium iodide (Figure 5A,B). However, each toxin greatly increased the death response that occurred after Tet withdrawal in I-Bax cells, indicating that each could augment the effect of Bax. The death response induced by the combination of Bax and antimycin could be almost completely suppressed by treatment with zVAD-fmk. Remarkably, however, zVAD-fmk yielded only a partial decrease in the response to Bax and oligomycin, so that a substantial rate of cell death was induced with this combination despite caspase blockade (Figure 5A,B). A similar effect was seen in mitochondria, where the combination of Tet withdrawal and oligomycin was uniquely able to provoke a loss of $\Delta \Psi_{\mathrm{m}}$ as measured using DiOC $_{6}$, despite treatment with zVAD-fmk (Figure 5C). Even the combination of $z V A D$-fmk with selective inhibitors of caspases 8 and 9 failed to prevent this cell death induced by 
A
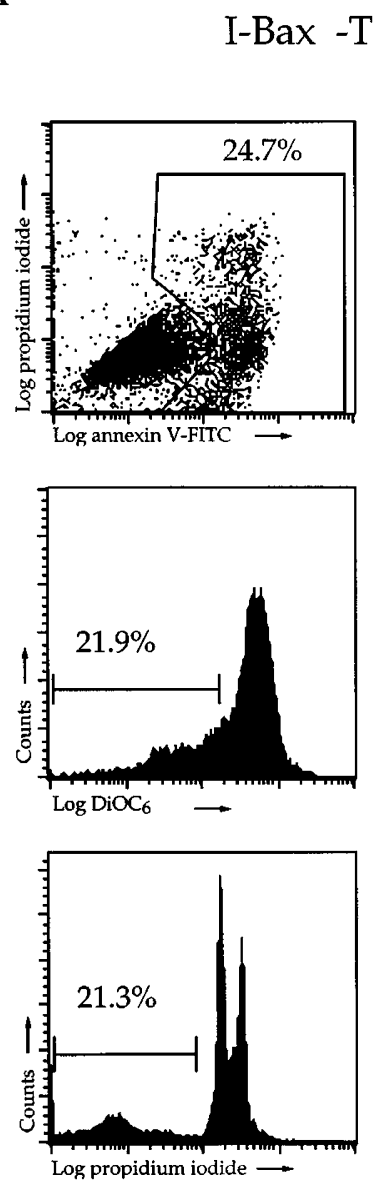

Control
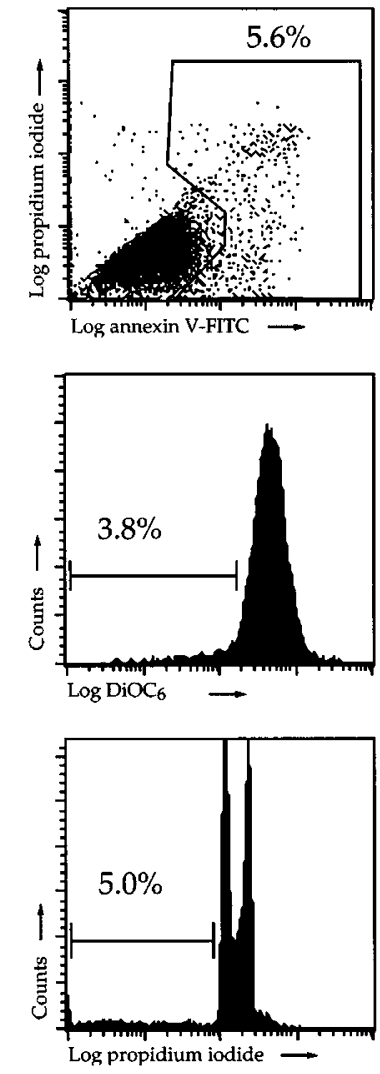

$+40 \mu \mathrm{M} z V A D-f m k$
B

+ Tet

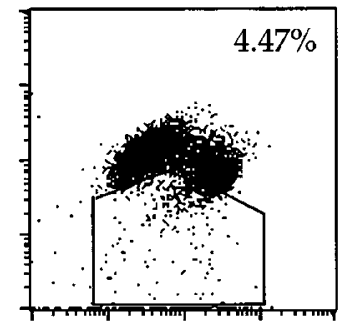

- Tet 24 hrs

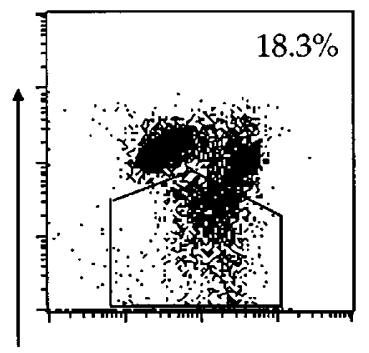

- Tet
+ zVAD
24 hrs

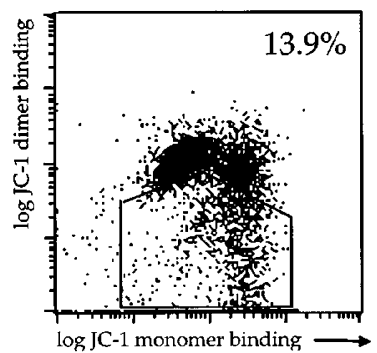

Figure 3 Caspase inhibition prevents Bax-induced apoptosis of I-Bax cells following withdrawal of Tet. (A) Inhibition of surface, mitochondrial, and nuclear changes. Cells were grown for $72 \mathrm{~h}$ without Tet, in either the absence (left panels) or presence (right panels) of zVAD-fmk. Apoptotic cells were scored by using FACS to assay binding of annexin V-FITC (upper panels), reduction in $\Delta \Psi_{m}$ as measured by DiOC fluorescence (middle panels), or the presence of subgenomic DNA contents as measured by propidium iodide staining of fixed cells (lower panels). The percentage of apoptotic cells is indicated in each panel. (B) JC-1 dye detects a caspase-independent effect of Bax on $\Delta \Psi_{m}$. I-Bax cells were grown either with or without Tet in the absence or presence of $z V A D$-fmk, then stained with JC-1 and analyzed by FACS to detect JC-1 monomer (green, horizontal axis) and dimer (red, vertical axis) fluorescence. Mitochondrial dysfunction is reflected in a loss of red JC-1 dimer emission, as these organelles must maintain $\Delta \Psi_{\mathrm{m}}>100 \mathrm{mV}$ in order to retain JC-1 dimers, whereas depolarized mitochondria can retain the monomer. Three replicate experiments all gave similar results. The results shown are from two experiments using essentially identical gating criteria for forward and side scatter

Bax and oligomycin, although it appeared to increase the number of necrotic cells (Figure 5D, upper right quadrant), as well as the larger proportion of cells which appear apoptotic (Figure 5D, lower right quadrant). These findings therefore define a caspase-independent pathway of cell death that yields many of the characteristic changes of apoptosis and is triggered by the combined effects of oligomycin and Bax.

\section{Role of the Bax BH3 domain}

Several studies have suggested that Bax and other proapoptotic members of the Bcl2 family have both $\mathrm{BH} 3-$ dependent and independent effects. ${ }^{16,22,23}$ We therefore asked whether the $\mathrm{BH} 3$ domain of Bax was required for its ability to cooperate with oligomycin in inducing caspase- independent death. To address this question, we constructed a series of plasmids encoding $\mathrm{HA}$-tagged chimeric proteins (Figure 6A) formed from selected regions of Bax (filled bars) and Bcl2 (open bars). The ability of these proteins to induce apoptosis independently of oligomycin was tested by transfecting each plasmid transiently into GM701 cells along with a reporter plasmid encoding $\beta$-galactosidase ( $\beta$-gal), then scoring the percentage of $\beta$-gal-positive cells that showed morphologic features of apoptosis $18 \mathrm{~h}$ later. ${ }^{24}$ As shown in Figure 6B, Bax itself induces apoptosis in approximately 55\% of cells in this assay, well above the background level obtained with $\mathrm{Bcl} 2$. We previously reported ${ }^{24}$ that a chimera termed $\mathrm{C} 10$, in which the $\mathrm{BH} 3$ domain of $\mathrm{Bcl} 2$ is replaced by that of Bax, also induces apoptosis efficiently. For this study, we created four additional chimeras in which progressively 


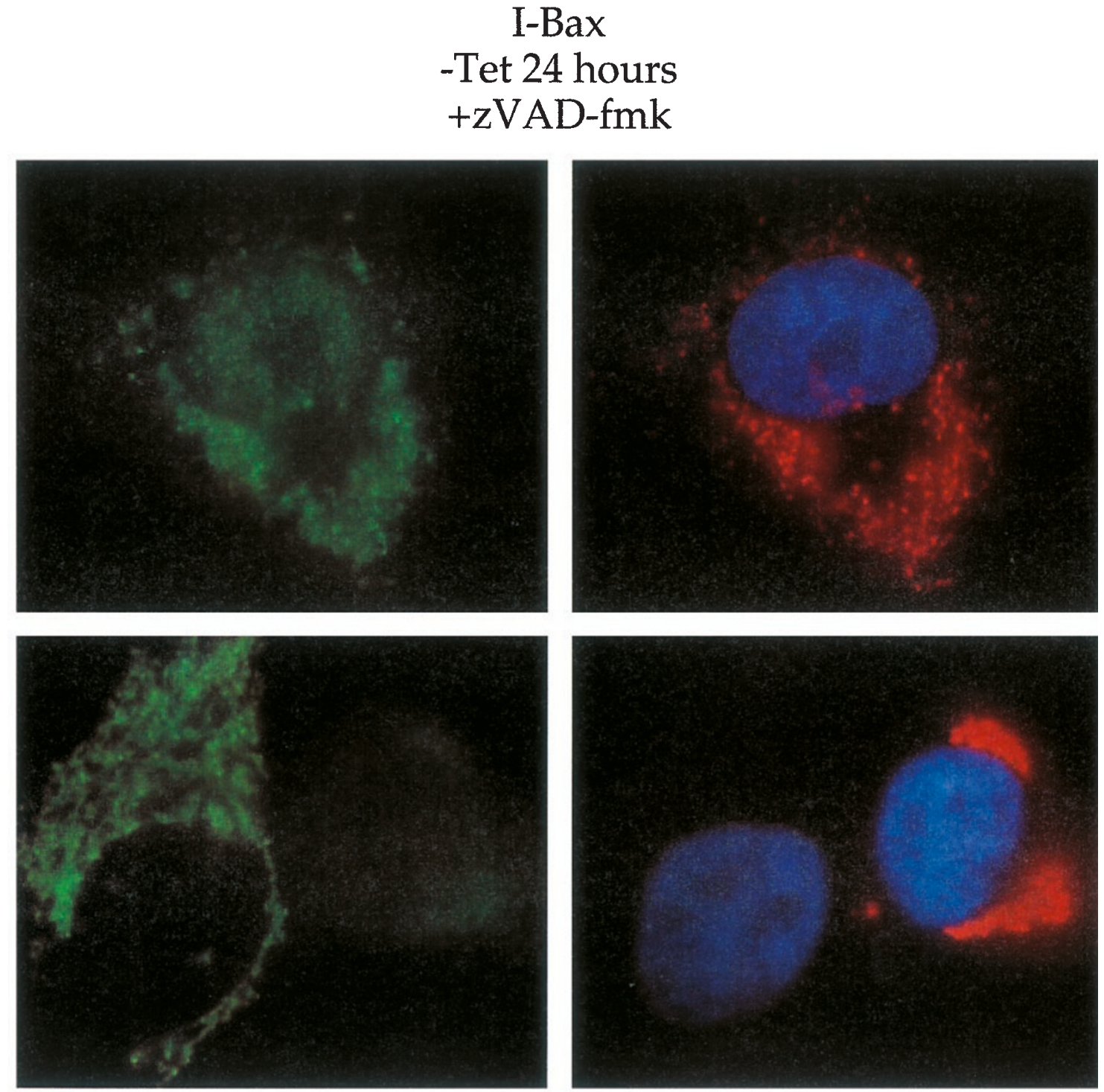

Figure $4 \mathrm{HABax}$ localizes to mitochondria and induces cyto $\mathrm{c}$ release via caspase-independent mechanisms. Immunofluorescence was performed using both a rhodamine-conjugated HA-specific antibody (red) and a primary mouse anti-cyto $\mathrm{c}$ antibody which was then secondarily stained with FITC-conjugated anti-mouse IgG (green). Nuclei were visualized with DAPI (blue). Each pair of micrographs depicts a single field showing cyto c (at left) or HA and nuclear staining (at right). IBax cells were examined $24 \mathrm{~h}$ after Tet-withdrawal. Upper and lower images are from the same plate; the upper pattern predominated at $16 \mathrm{~h}$, and the lower pattern at $72 \mathrm{~h}$ post-transfection

shorter sequences in and around the $\mathrm{BH} 3$ region from $\mathrm{Bcl} 2$ replaced the corresponding sequences in Bax; two of these (SW-3 and SW-4) contained the complete Bax BH3 domain, but the other two (SW-1 and SW-2) did not. All of the latter chimeras had proapoptotic activities comparable to that of Bax itself, except for SW-1, which was roughly half as active (Figure 6B).

We then assayed which of these mutants could synergize with oligomycin to induce caspase-independent death (Figure 6C). Each construct was transiently transfected into GM701 cells along with the $\beta$-gal reporter; $6 \mathrm{~h}$ later, zVAD-fmk was added to the culture medium either with or without oligomycin, and apoptosis-like morphologic changes were scored at $30 \mathrm{~h}$ after transfection. The background level of such changes was relatively high $(11-15 \%$ of cells) in these studies, presumably owing to the transient transfection itself and to the delayed addition of zVAD-fmk; this background was reduced (to $8 \%$ ) in the cells receiving Bcl2. Importantly, under these conditions, the addition of oligomycin significantly increased the rate of apoptosis-like morphology induced by Bax and by $\mathrm{C} 10$, but not by Bcl2. Of the remaining chimeras, $\mathrm{SW}-3$ and SW-4 were likewise able to synergize with oligomycin, but SW-1 and SW-2 did not. This suggested that residues critical for this synergy are located between positions 61 and 68 of Bax, a region that overlaps the $\mathrm{BH} 3$ domain 
A
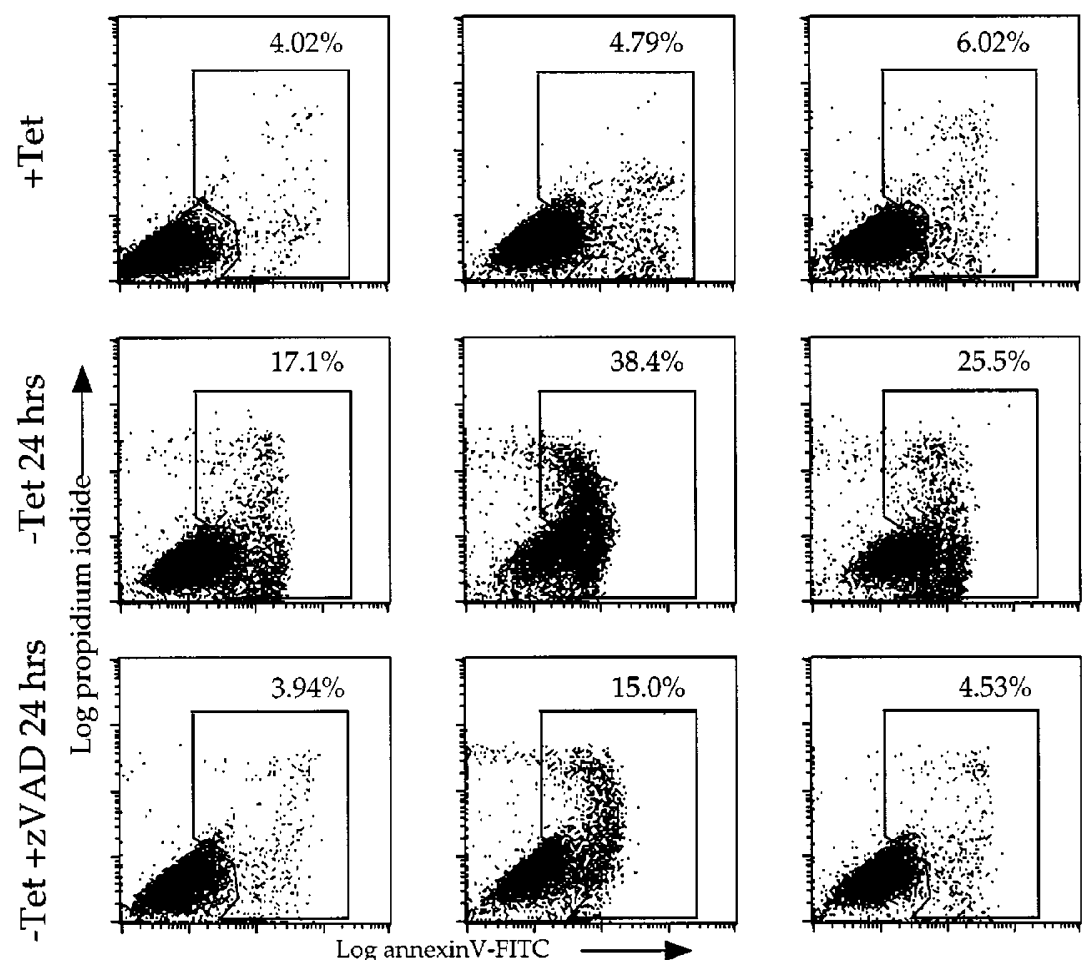

Control

$+5 \mu \mathrm{g} / \mathrm{ml}$ Oligo

$+10 \mu \mathrm{g} / \mathrm{ml}$ Anti

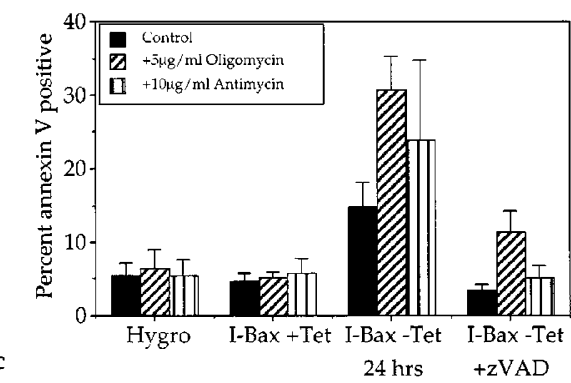

D
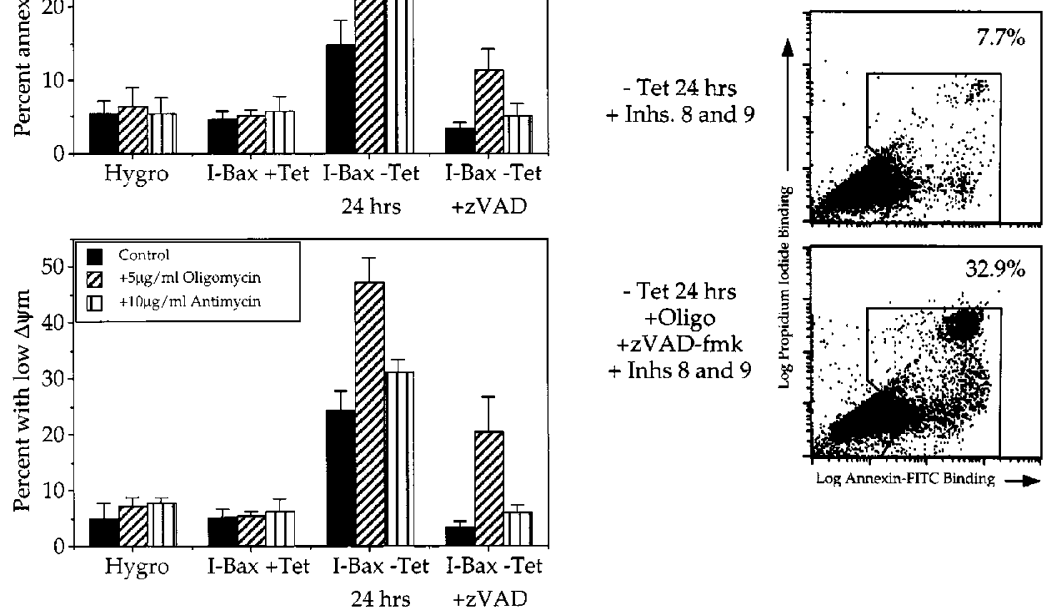

Figure 5 Mitochondria toxins augment HABax-induced apoptosis and can activate a caspase-independent apoptotic pathway. Cells were grown for $24 \mathrm{~h}$ in the presence or absence of Tet and of the mitochondrial toxins oligomycin (Oligo, at $5 \mu \mathrm{g} / \mathrm{ml}$ ) or antimycin (Anti, at $10 \mu \mathrm{g} / \mathrm{ml}$ ), then assayed for apoptosis by FACS. Where indicated, zVAD-fmk (zVAD) was added at the time of Tet withdrawal. (A) Oligomycin and antimycin each augment HABax-induced apoptosis, as detected by surface annexin V-FITC binding. I-Bax cells were grown under the conditions shown, then analyzed for annexin V-FITC binding (horizontal axis) and for uptake of propidium iodide (vertical axis). 'Control' denotes no added toxin. (B) Caspase-independent induction of annexin V-FITC binding by the combination of oligomycin treatment and Tet-withdrawal. The percentage ( \pm standard deviation) of surface annexin V-binding cells was assayed as in (A), either for Hygro cells (Hygro) or for I-Bax cells under the conditions indicated, in triplicate experiments. (C) Caspase-independent induction of mitochondrial dysfunction by the combination of oligomycin treatment and Tet-withdrawal. Cells grown under the indicated conditions were assayed for reduced $\Delta \Psi_{\mathrm{m}}$ as described for Figure $3 \mathrm{~A}$, in triplicate experiments \pm standard deviation. (D) Caspase inhibitors 8 (IETD-CHO) and 9 (LEHD-CHO) [Inhs 8 and 9 ] can inhibit Bax induced apoptosis as measured by surface annexin binding, but cannot inhibit Bax and oligomycin induced cell death. Forty $\mu \mathrm{M}$ each of Inhs 8 and 9 with or without $40 \mu \mathrm{M}$ zVAD-fmk and oligomycin was added at the time of Tet withdrawal 
A

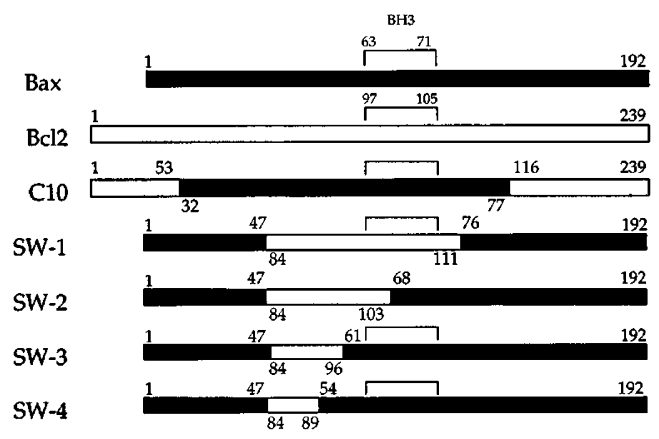

B

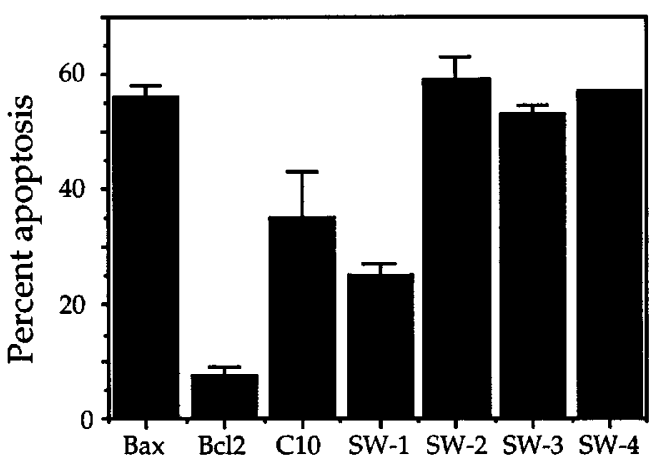

C

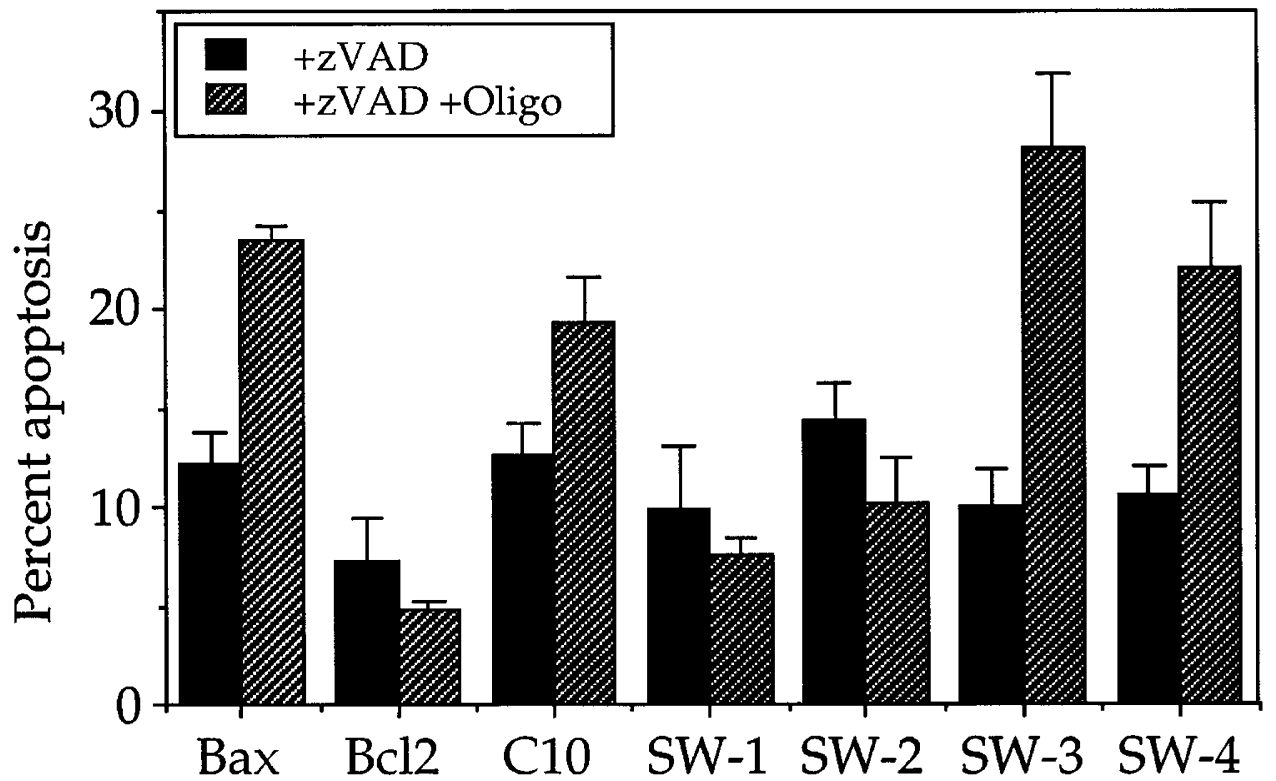

Figure 6 The BH3 domain of Bax is required for synergy with oligomycin. (A) Schematic view of Bax (filled bars), Bcl2 (open bars), and four chimeric proteins tested in this study. Key residues are numbered above and below each construct. Complete BH3 domains, where present, are indicated by brackets; SW-2 contains portions of the BH3 domains of both Bax and Bcl2. All of these constructs carried an N-terminal HA-epitope tag (not shown). (B) Apoptogenic activities of the tested constructs. Plasmids encoding the indicated proteins were transiently transfected along with a $\beta$-gal expression plasmid into GM701 cells, which were then scored morphologically for apoptosis at $18 \mathrm{~h}$ post-transfection. Data shown are mean \pm standard deviation for three assays. (C) Caspase-independent apoptosis. GM701 cells were transiently transfected with the indicated constructs, then treated $6 \mathrm{~h}$ later with zVAD-fmk with or without oligomycin, and then assayed for apoptosis as in $(B)$, at $28 \mathrm{~h}$ post-transfection. Data shown are mean \pm standard deviation for four assays

(residues 63-71). Together, these results indicate that an intact $\mathrm{Bax} \mathrm{BH} 3$ domain is critical for activating caspaseindependent death in cooperation with oligomycin.

\section{Structural requirements for other mitochondrial effects}

To determine if any of the other effects we had observed in mitochondria could be mapped to particular domains in Bax, we performed immunofluorescence analyses in GM701 cells transiently transfected with the various Bax/
Bcl2 chimeras. Representative results are shown in Figure 7. By $24 \mathrm{~h}$ post-transfection, wild-type Bax, as well as chimeras SW1 through SW4 had localized to mitochondria and induced cyto $\mathrm{c}$ release, as judged by a lack of costaining with the cyto $c$ antibody (Figure 7 and data not shown). Because SW1 and SW2 each lack all or part of the $\mathrm{Bax} \mathrm{BH} 3$ domain, these findings confirm earlier evidence that this domain is not required for mitochondrial localization. ${ }^{22}$

Interestingly, unlike the other chimeras, SW1 clearly failed to cause clumping of mitochondria (Figure 7), 

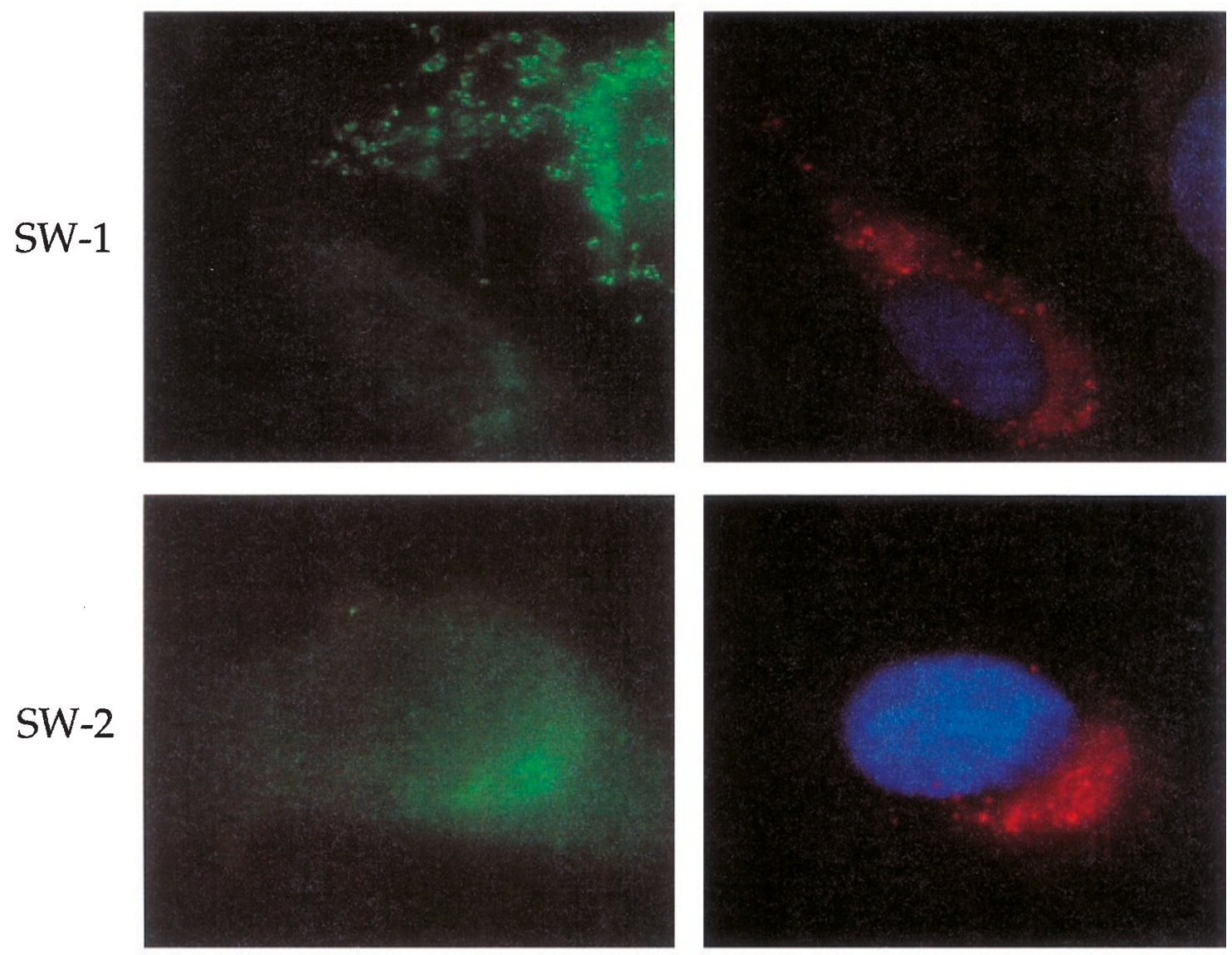

\section{cytochrome c}

\section{HA/DAPI}

Figure 7 Subcellular localization of Bax/Bcl2 chimeras, and their mitochondrial effects in zVAD-fmk-treated cells. Immunofluorescence was performed as in Figure 4. Sequences in or around the $\mathrm{Bax} \mathrm{BH} 3$ domain are necessary to induce mitochondrial clumping. Fluorescence micrographs of representative individual cells transiently expressing the indicated HA-tagged constructs were treated with ZVAD-fmk and then examined $24 \mathrm{~h}$ post-transfection. The upper panel depicts an HA-positive cell on the left and an HA-negative cell on the right, the latter illustrating the typical punctate staining pattern of intramitochondrial cyto $c$

suggesting that Bax residues at positions 68-76 might be required for this effect.

\section{BH3 point mutants and caspase-independent death}

We also tested three missense mutants of Bax, each of which contained alanines in place of two consecutive residues within the $\mathrm{BH} 3$ domain (Figure $8 \mathrm{~A}$ ). When transiently expressed in GM701 cells, all three mutants induced apoptosis at least as efficiently as wild-type Bax (data not shown). Moreover, all three associated with mitochondria and induced both clumping (Figure 8B and data not shown) and cyto $c$ release. However, only one mutant (BaxDE) was capable of synergizing with oligomycin to induce death in the presence of zVADfmk (Figure 8A). As the latter mutation involved two residues that are each specifically required for the $\mathrm{BH}$ mediated dimerization of $\mathrm{Bax}$ with $\mathrm{Bcl} 2,{ }^{25}$ this implies that no such interaction is needed to support caspaseindependent death.

\section{Discussion}

We have created and characterized a stably transfected cell line, derived from human GM701 fibroblasts, that inducibly expresses the proapoptotic protein Bax. When Bax is induced, these cells undergo a classic apoptotic response that can be completely inhibited by pharmacologically blocking caspase activation. This strict caspase-dependence is compatible with the view that $\mathrm{Bax}$, like other $\mathrm{BH}$-containing death agonists, acts primarily by inducing release of cyto $c$ or other factors from mitochondria, which lead to activation of upstream caspases, and then to the propagation of apoptosis through activation of downstream caspases. ${ }^{1,2}$ Surprisingly, however, we find that treatment with oligomycin - a mitochondrial toxin which, at the dosage we used, fails to cause apoptosis by itself-efficiently triggers death of the Bax- 
A

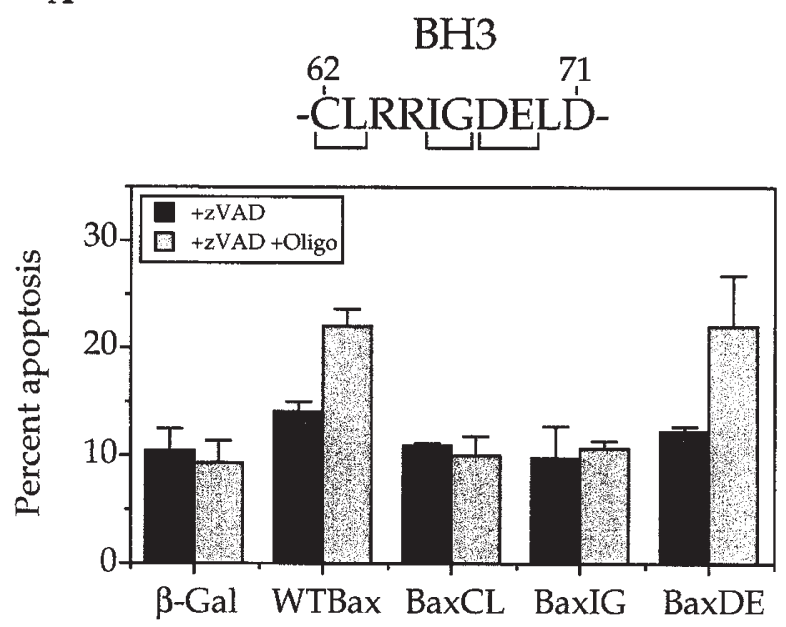

B
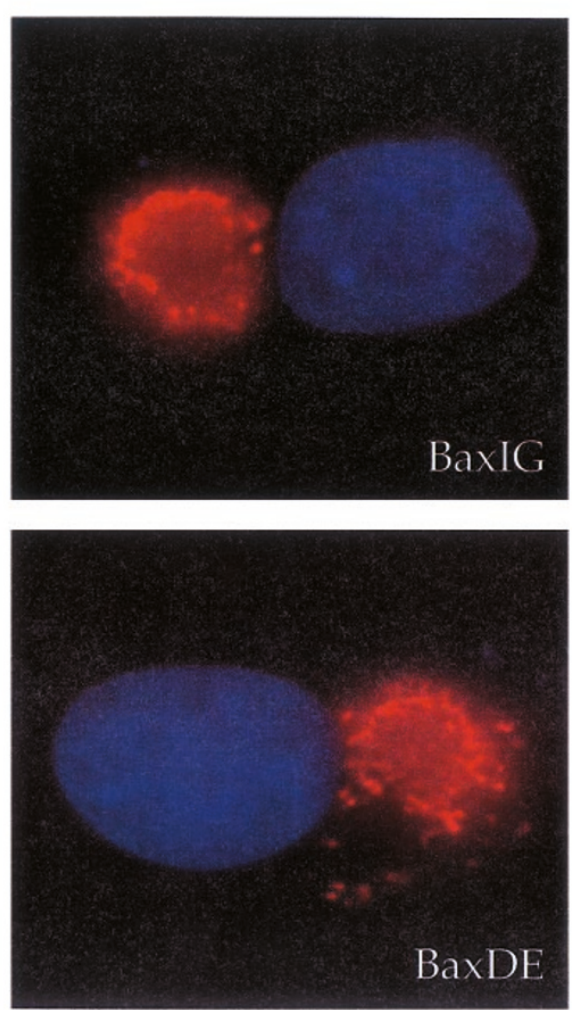

Figure 8 Bax sequences required for caspase-independent killing are distinct from those mediating mitochondrial relocalization. (A) Effect of $\mathrm{BH} 3$ point mutations on caspase-independent killing in synergy with oligomycin. Sequence of the wild-type $\mathrm{Bax} \mathrm{BH} 3$ region is shown at top; brackets indicate three pairs of residues that were replaced by paired alanines to create the three mutants. Below, the apoptogenic activity of each mutant and of vector alone is assayed in GM701 cells treated with zVAD-fmk with or without oligomycin, as in Figure 6. Data are mean \pm standard deviation for quadruplicate assays. (B) Fluorescence micrographs of representative individual cells transiently expressing the indicated Bax mutants in the presence of zVAD-fmk, and stained for HABax (red) and nuclear DNA (blue) as described for Figure 4

expressing cells even when caspases are inhibited. Cells dying under the latter conditions exhibit several of the defining features of apoptosis, including surface annexin $\mathrm{V}$ binding, cytoplasmic shrinkage, and mitochondrial dysfunction. These findings verify the existence of a robust, caspase-independent pathway of death resembling apoptosis, and they provide an experimental model system in which to study this pathway in isolation. They also imply that a key element of this pathway emanates from mitochondria.

Our results confirm and complement earlier reports ${ }^{19,20}$ of caspase-independent death caused by Bax. In those studies, which employed the T-lymphocyte line Jurkat, overexpressing Bax alone was sufficient to cause rapid cell death that occurred despite treatment with zVAD-fmk at dosages that effectively blocked both Bax-induced caspase activation and Fas-mediated apoptosis. This suggests that, in Jurkat cells, Bax simultaneously activates two parallel pathways-one caspase-dependent, the other caspaseindependent-that can each lead independently to death. By contrast, our study indicates that, in GM701 fibroblasts, Bax alone triggers only caspase-dependent death, whereas caspase-independent killing requires both $\mathrm{Bax}$ and $\mathrm{a}$ second signal that can be supplied by oligomycin. A likely interpretation is that there are important tissue-specific differences in regulation of the two pathways. Consistent with that view, earlier studies of caspase-9-deficient knockout mice found that thymocytes from such animals were sensitive to radiation-induced apoptosis but that embryonic fibroblasts were not, suggesting that $T$ cells are better able to access an alternative death pathway. ${ }^{26,27}$

Our data extend earlier results by showing that the $\mathrm{BH} 3$ domain in Bax is strictly required for its ability to activate caspase-independent death in cooperation with oligomycin. This is in contrast to other properties of Bax, such as mitochondrial localization and the induction of cyto $c$ release, which do not require an intact $\mathrm{BH} 3$ region. Bax's role in activating the second pathway may thus reflect its ability to lower $\Delta \Psi_{\mathrm{m}}$, which is known to be BH3dependent, ${ }^{22}$ or to form ion channels in cellular membranes. ${ }^{28,29}$ In our cells, induction of wild-type Bax causes mitochondria to aggregate in a perinuclear region of the cytoplasm; our mutational analysis maps this clumping response to residues in, or immediately downstream of, the $\mathrm{BH} 3$ domain. Li et al. ${ }^{15}$ have previously noted mitochondrial clumping during the apoptotic response to tBID, another death agonist that contains a $\mathrm{BH} 3$ domain. The mechanism of this BH3-dependent clumping is unclear: as similar clumping can also be produced by genetic defects in microtubules, ${ }^{30}$ it may result from selective detachment of mitochondria away from the microtubular network, or from destruction of microtubules themselves in apoptotic cells. Our data indicate that Bax-induced mitochondrial clumping can occur when caspases are inhibited, but they do not reveal whether such clumping contributes to caspaseindependent killing. Significantly, however, we find that another known function of the Bax $\mathrm{BH} 3$ domain - the ability to associate physically with $\mathrm{Bcl} 2$-is probably not necessary for activation of this alternative pathway: although previous studies have shown that replacing $\mathrm{Bax} \mathrm{BH} 3$ residues 68 or 69 individually with alanine prevents binding to $\mathrm{Bcl} 2$ in vitro, we find that mutating both these residues simultaneously does not prevent the caspase-independent response (Figure 8A). 
Oligomycin acts on the $F_{1} F_{0}$-ATPase of the mitochondrial inner membrane, which utilizes the energy stored in the transmembrane proton gradient to convert ADP to ATP. By blocking this enzyme, oligomycin prevents dissipation of the proton gradient and causes mitochondrial hyperpolarization. A functional linkage between Bax and $F_{1} F_{0}$-ATPase was previously suggested on genetic grounds, based on a study of Bax-induced killing in yeast, ${ }^{31}$ but its biochemical basis remains uncertain. The fact that certain point mutants of Bax lose the oligomycin effect we describe suggests that it may be a specific protein-protein interaction between Bax and a component of the mitochondria that is responsible for caspase-independent cell death. Recent studies suggest that Bax binds and inhibits the mitochondrial ATP/ADP antiporter, which pumps ATP out of the organelle in exchange for ADP. ${ }^{32}$ It may be that, by blocking import of ADP, Bax reduces the availability of this $F_{1} F_{0}$-ATPase substrate, and so enhances vulnerability to oligomycin. Consistent with this model, Bcl-XL, an antagonist of Bax, prevents oligomycin-induced hyperpolarization of mitochondria. $^{33}$ Bax has also been shown to bind to the mitochondrial voltage dependent anion channel (VDAC) and enable the passage of cyto $c$ through this pore. ${ }^{34}$ In our system, cyto $c$ release and cooperation with oligomycin appear to map to different regions of Bax, suggesting that Bax could potentially interact with multiple components of the mitochondria and cause the release of several factors that each activate separate death pathways. In this regard, Susin et al. ${ }^{5}$ have recently reported purification of apoptosis inducing factor (AIF), a 57-kilodalton flavoprotein that normally resides in the mitochondrial intermembranous space but can be released to the cytoplasm in response to apoptotic stimuli. Once released, AIF potently induces chromatin condensation, large-scale chromosomal fragmentation, loss of $\Delta \Psi_{\mathrm{m}}$, and exposure of surface phosphatidylserine; most significantly, these activities are all resistant to inhibition by zVAD-fmk. The effects of AIF, which closely mirror those we observed in oligomycin/ zVAD-fmk treated I-Bax cells, illustrate that many of the classic features of apoptosis can occur without caspase activation. It remains to be determined whether it is AIF itself or some other, as-yet-unidentified mitochondrial products that mediate caspase-independent killing of these cells.

\section{Materials and Methods}

\section{Cell lines}

The human GM701 fibroblast line and all clones derived from it were maintained in Dulbecco's modified Eagle's medium (DMEM) supplemented with penicillin $(100 \mathrm{U} / \mathrm{ml})$, streptomycin $(0.1 \mathrm{mg} / \mathrm{ml})$, glutamate $(2 \mathrm{mM})$ and $10 \%(\mathrm{v} / \mathrm{v})$ fetal calf serum. All cells were maintained at $37^{\circ} \mathrm{C}$ in $5 \% \mathrm{CO}_{2}$ at $90 \%$ relative humidity. To establish Bax-inducible lines, GM701 cells were first transfected by electroporation with pTET-Off regulatory plasmid (Clontech PT 3001-1), and a stable clone was selected according to the manufacturer's protocol. The pTRE-HABax response plasmid was constructed by inserting a murine bax cDNA with an N-terminal influenza hemagglutinin (HA) epitope tag (YPYDVPDYA) into the EcoRl-Xbal sites of pTRE (Clontech). pTRE-HABax was transfected into the stable pTET-Off line along with a pTK-hygromycin selection plasmid. Stable transfectants were selected in $5 \mu \mathrm{g} / \mathrm{ml}$ tetracycline (Tet) and $0.2 \mathrm{mg} /$ $\mathrm{ml}$ hygromycin, and then screened for cell death upon withdrawal of Tet. All Tet-dependent clones were supplemented with $5 \mu \mathrm{g} / \mathrm{ml}$ Tet every 1-2 days. To remove Tet, cells were washed in phosphatebuffered saline (PBS), trypsinized (0.25\%), and resuspended in PBS, pelleted at $1000 \times g$ for $5 \mathrm{~min}$, and then replated in fresh media. ZVADfmk and other caspase inhibitors were used at $40 \mu \mathrm{M}$ each, and were replenished daily whenever used for longer than $24 \mathrm{~h}$.

\section{Reagents}

Rhodamine-conjugated anti-HA (12CA5) and FITC-conjugated goat anti-mouse sera were purchased from Boehringer Mannheim. Antihuman PARP (clone C2-10) and anti-cytochrome c (7H8.2C12) monoclonal antibodies were purchased from Pharmingen. Anti-Bax polyclonal antibody (P-19) was purchased from Santa Cruz Biotechnology. Antibodies were used at dilutions recommended by the suppliers. Propidium iodide, oligomycin, antimycin, and saponin were from Sigma; tetracycline, hygromycin, caspase-8 inhibitor I (IETD-CHO), caspase-9 inhibitor II (LEHD-CHO), and annexin V-FITC were from Calbiochem; zVAD-fmk was from Alexis Laboratories; $\mathrm{DiOC}_{6}, \mathrm{JC}-1$, and Mitotracker Green were from Molecular Probes.

\section{Western blot analysis}

Cells were lysed in Triton-X lysis buffer $(150 \mathrm{mM} \mathrm{NaCl}, 10 \mathrm{mM}$ Tris, pH 7.4, 5 mM EDTA, 1\% [v/v] Triton X-100, $5 \mu \mathrm{g} / \mathrm{ml}$ leupeptin, $1 \mu \mathrm{g} / \mathrm{ml}$ pepstatin, and $0.5 \mathrm{mM}$ Pefabloc [Boehringer Mannheim]). Aliquots containing 30-50 $\mu \mathrm{g}$ protein were fractionated by SDS-polyacrylamide gel electrophoresis (PAGE) and transferred to Hybond filters (Amersham). Filters were pre-blocked for $15 \mathrm{~min}$ in Blotto (PBS with $3 \%[\mathrm{v} / \mathrm{v}]$ Carnation milk, 0.1\% [v/v] Tween-20), then incubated for $1 \mathrm{~h}$ with primary antibodies in Blotto. Filters were then washed three times in PBS with $0.1 \%$ Tween-20 for $10 \mathrm{~min}$ each, incubated with secondary antisera in Blotto for $1 \mathrm{~h}$, washed again three times, and developed using ECL reagent (Pierce).

\section{RNA preparation and Northern blot analysis}

RNA was isolated using the Trizol reagent (GibcoBRL). Aliquots $(10 \mu \mathrm{g})$ were fractionated on formaldehyde/agarose gels, which were then soaked in water for $20 \mathrm{~min}$ and then soaked for an additional $15 \mathrm{~min}$ in $20 \times$ standard saline citrate (SSC, $1 \times \mathrm{SSC}$ is $150 \mathrm{mM} \mathrm{NaCl}$, $15 \mathrm{mM}$ sodium citrate, $\mathrm{pH}$ 7.0). RNA was transferred overnight onto Hybond paper (Amersham) by capillary action, and crosslinked to it with ultraviolet light. Hybridization was done using radiolabelled DNA probes in ExpressHyb (Clontech) according to manufacturer's instructions, and detected by autoradiography. The HABax probe was a unique $\mathrm{Kpnl} / \mathrm{Bg} / \mathrm{ll}$ fragment of pTRE-HABax. Glyceraldehyde 6phosphate dehydrogenase (GAPDH) mRNA was detected with a Pstl/ Hindlll fragment of GAPDH cDNA.

\section{Metabolic labeling}

Six hours before harvest, the media of the cells was changed to methionine-free DMEM containing $10 \%$ dialyzed fetal calf serum, $100 \mu \mathrm{Ci} / \mathrm{ml}$ of ${ }^{35} \mathrm{~S}$-methionine (Amersham). Cells were harvested in Triton-X lysis buffer, and lysates were precleared overnight with $30 \mu \mathrm{l}$ 
of ProteinA/G-Plus Agarose beads (Santa Cruz Biologicals). The following day, antibody was added and incubated for $3 \mathrm{~h}$ at room temperature, then $30 \mu \mathrm{l}$ agarose beads were added for $3 \mathrm{~h}$. Beads were washed three times in Triton-X lysis buffer, then eluted in $1 \times$ SDS sample buffer. Samples were fractionated on 14\% PAGE gels, which were then fixed, treated for 30 min with AmplifyTM (Amersham), and analyzed by autoradiography.

\section{Assessment of apoptosis by fluorescence activated cell sorting (FACS)}

Both floating and adherent cells were analyzed in all assays. For annexin $\mathrm{V}$ binding, cells were harvested using trypsin and then incubated with annexin V-FITC according to the manufacturer's instructions. For determination of DNA content, cells were harvested using trypsin, washed in PBS, pelleted, resuspended in $500 \mu$ PBS, and then fixed by dropwise addition of $3 \mathrm{ml}$ ice-cold $70 \%$ ethanol. After fixing for at least $30 \mathrm{~min}$ on ice, cells were washed in PBS, resuspended in PBS containing $20 \mu \mathrm{g} / \mathrm{ml}$ ribonuclease A and $20 \mu \mathrm{g} /$ $\mathrm{ml}$ propidium iodide, and then incubated for $15 \mathrm{~min}$ at room temperature before analysis. For analysis of mitochondrial function, either $50 \mathrm{nM} \mathrm{DiOC}_{6}$ or $10 \mu \mathrm{g} / \mathrm{ml} \mathrm{JC}-1$ dye was added to the media, and cells were harvested by trypsin 15 min later and resuspended in PBS and analyzed immediately. All samples were analyzed using a BectonDickinson FACSort and Cellquest software, examining a minimum of 10000 cells in each sample.

\section{Transient transfection studies}

To create chimeras SW1-SW4, a HindlII restriction site was introduced into basepairs $135-138$ of a pSFFV-HABax/ $\beta$-galactosidase expression plasmid, ${ }^{24}$ resulting in missense mutation of threonine to serine at Bax residue 46. Fragments of $b c / 2$ were cloned into bax by PCR using this Hindlll site and the Pstl site at basepair 226. Double alanine mutations were also introduced by PCR. Transient transfections were performed as described. ${ }^{24}$ Where indicated, zVAD-fmk and oligomycin were added $6 \mathrm{~h}$ after transfection.

\section{Indirect immunofluorescence}

I-Bax cells treated as described or GM701 cells transfected as described were grown on glass cover slips, and fixed in $2 \%$ paraformaldehyde in PBS. Cells were washed in PBS with $0.03 \%$ saponin, then permeablized in PBS with $0.1 \%$ saponin and $1 \%$ BSA. Cells were double-labeled first with anti-cytochrome $c$ at 1:75 dilution and FITC-conjugated goat anti-mouse IgG at 1:50 dilution, and then with rhodamine-conjugated anti-HA at 1:20 dilution. DAPI was added in the mounting medium (Vectashield, Vector Laboratories). Cells were examined using a Nikon Eclipse TE300 microscope and IP Lab Spectrum software (Scanalytics, Inc.) To quantify 'clumping,' I-Bax cells were deprived of Tet and treated with $40 \mu \mathrm{M}$ zVAD-fmk. After 24 or $72 \mathrm{~h}$, the cells were fixed and probed as described above, and 300 HA-positive cells were examined in each case. In general, all HApositive mitochondria that were clumped were also negative for cyto $\mathrm{C}$ (see Figure 4, lower panel), whereas those found dispersed in the cytoplasm were variably either positive or negative for intramitochondrial cyto $\mathrm{c}$.

\section{Acknowledgments}

This work was supported in part by NIH grants Al36636 and Al40317, and by the Barbara Fasken Memorial Fellowship from the Prairie Foundation. We thank Zeneida Mosquera for technical assistance.

\section{References}

1. Green DR and Reed JC. (1998) Mitochondria and apoptosis. Science 281: $1309-1312$

2. Liu X, Kim CN, Yang J, Jemmerson R and Wang X. (1996) Induction of apoptotic program in cell-free extracts: requirement for dATP and cytochrome c. Cell. 86: 147-157

3. Li P, Nijhawan D, Budihardjo I, Srinivasula SM, Ahmad M, Alnemri ES and Wang X. (1997) Cytochrome $c$ and dATP-dependent formation of Apaf-1/caspase-9 complex initiates an apoptotic protease cascade. Cell 91: 479-489

4. Susin SA, Zamzami N, Castedo M, Hirsch T, Marchetti P, Macho A, Daugas E, Geuskens Mand Kroemer G. (1996) Bcl-2 inhibits the mitochondrial release of an apoptogenic protease. J. Exp. Med. 184: 1331-1341

5. Susin SA, Lorenzo HK, Zamzami N, Marzo I, Snow BE, Brothers GM, Mangion J, Jacotot E, Costantini P, Loeffler M, Larochette N, Goodlett DR, Aebersold R, Siderovski DP, Penninger JM and Kroemer G. (1999) Molecular characterization of mitochondrial apoptosis-inducing factor. Nature 397: 441-446

6. Susin SA, Lorenzo HK, Zamzami N, Marzo I, Brenner C, Larochette N, Prevost MC, Alzari PM and Kroemer G. (1999) Mitochondrial release of caspase-2 and -9 during the apoptotic process. J. Exp. Med. 189: 381-394

7. Bossy-Wetzel E, Newmeyer DD and Green DR. (1998) Mitochondrial cytochrome $\mathrm{c}$ release in apoptosis occurs upstream of DEVD-specific caspase activation and independently of mitochondrial transmembrane depolarization. EMBO J. 17: 37-49

8. Adams JM and Cory S. (1998) The Bcl-2 protein family: arbiters of cell survival. Science 281: $1322-1326$

9. Chao DT and Korsmeyer SJ. (1998) BCL-2 family: regulators of cell death. Annu. Rev. Immunol. 16: 395-419

10. Kluck RM, Bossy-Wetzel E, Green DR and Newmeyer DD. (1997) The release of cytochrome c from mitochondria: a primary site for $\mathrm{Bcl}-2$ regulation of apoptosis. Science 275: $1132-1136$

11. Yang J, Liu X, Bhalla K, Kim CN, Ibrado AM, Cai J, Peng TI, Jones DP and Wang X. (1997) Prevention of apoptosis by Bcl-2: release of cytochrome c from mitochondria blocked. Science 275: 1129-1132

12. Hsu YT, Wolter KG and Youle RJ. (1997) Cytosol-to-membrane redistribution of Bax and Bcl-X(L) during apoptosis. Proc. Natl. Acad. Sci. USA. 94: 3668-3672

13. Wolter KG, Hsu YT, Smith CL, Nechushtan A, Xi XG and Youle RJ. (1997) Movement of Bax from the cytosol to mitochondria during apoptosis. J. Cell. Biol. 139: $1281-1292$

14. JurgensmeierJM, XieZ, Deveraux Q, Ellerby L, Bredesen D and Reed JC. (1998) Bax directly induces release of cytochrome $\mathrm{c}$ from isolated mitochondria. Proc. Natl. Acad. Sci. USA. 95: 4997-5002

15. LiH, ZhuH, Xu CJand Yuan J. (1998) Cleavage of BID by caspase 8 mediates the mitochondrial damage in the Fas pathway of apoptosis. Cell 94: 491-501

16. Luo X, Budihardjo I, Zou H, Slaughter C and Wang X. (1998) Bid, a Bcl2 interacting protein, mediates cytochrome $\mathrm{c}$ release from mitochondria in response to activation of cell surface death receptors. Cell. 94: 481-490

17. Narita M, Shimizu S, Ito T, Chittenden T, Lutz RJ, Matsuda H and Tsujimoto $Y$. (1998) Bax interacts with the permeability transition pore to induce permeability transition and cytochrome $\mathrm{c}$ release in isolated mitochondria. Proc. Natl. Acad. Sci. USA. 95: 14681-14686

18. Rosse T, Olivier R, Monney L, Rager M, Conus S, Fellay I, Jansen B and Borner C. (1998) Bcl2 prolongs cell survival after Bax induced release of cytochrome C. Nature 391: 496-499.

19. Xiang J, Chao DT and Korsmeyer SJ. (1996) BAX-induced cell death may not require interleukin 1 beta-converting enzyme-like proteases. Proc. Natl. Acad. Sci. USA. 93: 14559-14563

20. Pastorino JG, Chen ST, Tafani M, Snyder JW and Farber JL. (1998) The overexpression of Bax produces cell death upon induction of the mitochondrial permeability transition. J. Biol. Chem. 273: 7770-7775

21. Zha H, Fisk HA, Yaffe MP, Mahajan N, Herman B and Reed JC. (1996) Structurefunction comparisons of the proapoptotic protein Bax in yeast and mammalian cells. Mol. Cell Biol. 16: 6494-6508

22. Han J, Modha D and White E. (1998) Interaction of E1B 19K with Bax is required to block Bax-induced loss of mitochondrial membrane potential and apoptosis. Oncogene 17: 2993-3005

23. Chou JJ, Li H, Salvesen GS, Yuan J and Wagner G. (1999) Solution structure of BID, an intracellular amplifier of apoptotic signaling. Cell 96: 615-624 
24. Hunter JJ and Parslow TG. (1996) A peptide sequence from Bax that converts $\mathrm{Bcl}-2$ into an activator of apoptosis. J. Biol. Chem. 271: $8521-8524$

25. Zha H and Reed JC. (1997) Heterodimerization-independent functions of cell death regulatory proteins $\mathrm{Bax}$ and $\mathrm{Bcl}-2$ in yeast and mammalian cells. J. Biol. Chem. 272: $31482-31488$

26. Hakem R, Hakem A, Duncan GS, Henderson JT, Woo M, Soengas MS, Elia A, de la Pompa JL, Kagi D, Khoo W, Potter J, Yoshida R, Kaufman SA, Lowe SW Penninger JM and Mak TW. (1998) Differential requirement for caspase 9 in apoptotic pathways in vivo. Cell 94: 339-352

27. Kuida K, HaydarTF, Kuan CY, GuY, Taya C, Karasuyama H, Su MS, Rakic P and Flavell RA. (1998) Reduced apoptosis and cytochrome c-mediated caspase activation in mice lacking caspase 9. Cell 94: 325-337

28. Antonsson B, Conti F, Ciavatta A, Montessuit S, Lewis S, Martinou I, Bernasconi L, Bernard A, Mermod JJ, Mazzei G, Maundrell K, Gambale F, Sadoul R and Martinou JC. (1997) Inhibition of Bax channel-forming activity by Bcl-2. Science $277: 370-372$

29. Schlesinger PH, Gross A, Yin XM, Yamamoto K, Saito M, Waksman G and Korsmeyer SJ. (1997) Comparison of the ion channel characteristics of proapoptotic BAX and antiapoptotic BCL-2. Proc. Natl. Acad. Sci. USA. 94: $11357-11362$
30. Tanaka Y, Kanai Y, Okada Y, Nonaka S, Takeda S, Harada A and Hirokawa N. (1998) Targeted disruption of mouse conventional kinesin heavy chain, kif5B, results in abnormal perinuclear clustering of mitochondria. Cell 93: 1147-1158

31. Matsuyama S, Xu Q, Velours J and Reed JC. (1998) The Mitochondrial F0F1ATPase proton pump is required for function of the proapoptotic protein Bax in yeast and mammalian cells. Mol. Cell. 1: $327-336$

32. Marzo I, Brenner C, Zamzami N, Jurgensmeier JM, Susin SA, Vieira HL, Prevost MC, Xie Z, Matsuyama S, Reed JC and Kroemer G. (1998) Bax and adenine nucleotide translocator cooperate in the mitochondrial control of apoptosis. Science 281: $2027-2031$

33. Vander Heiden MG, Chandel NC, Williamson EK, Schumacker PT and Thompson CB. (1997) Bcl-xL regulates the membrane potential and volume homeostasis of mitochondria. Cell. 91: 627-637

34. Shimizu S, Narita M and Tsujimoto Y. (1999) Bcl-2 family proteins regulate the release of apoptogenic cytochrome $c$ by the mitochondrial channel VDAC Nature 399: $483-487$ 